\title{
一論 文—
}

（日本化学会誌，1991，（4)， p. 336３41）

(C) 1991 The Chemical Society of Japan

\section{ポリアミン置換メチルホスホン酸残基を持った キレート樹脂のウラン $(\mathbf{V I})$ 吸着特性 ${ }^{12)}$}

\author{
（1990 年 12 月 12 日 受理）
}

松田 公 昭*.秋 吉 芳 郎**

ポリアミン置換メチルホスホン酸残基を持ったキレート樹脂 (APA) の硫酸, リン酸, 海水中のウラ ン(U)吸着特性を調べた。比較のためにホスホン酸残基，ウラン $(\mathrm{V})$ 回収用として工業的に使用されて いる第四級アンモニウム残基を持ったイオン交換樹脂および各種抽出試薬のウラン(VI)吸着性をあわせ て調べた。100 $\mathrm{g} \cdot \mathrm{dm}^{-3}$ 硫酸, $300 \mathrm{~g} \cdot \mathrm{dm}^{-3}$ リン酸, 海水の各水溶液中の $100 \mathrm{mg} \cdot \mathrm{dm}^{-3}$ ウラン (VI)濃度 における APA のウラン吸着容量は，それぞれ $0.2,0.05,0.05 \mathrm{mmol}^{\circ} \mathrm{g}^{-1}$ であった。APA のウラン (VI)吸着容量は，ホスホン酸残基を持ったイオン交換樹脂の海水中ウラン $(\mathrm{V})$ 吸着 $\left(0.2 \mathrm{mmol} \cdot \mathrm{g}^{-1}\right)$ を 除き他の何れの吸着剤よりも大きかった。APA のウラン $(\mathrm{V})$ 吸着速度は速く, 処理時間 $(t: \min )$ と $100 \mathrm{~g} \cdot \mathrm{dm}^{-3}$ 硫酸水溶液中のウラン $(\mathrm{V})$ 濃度 $\left(y: \mathrm{mg} \cdot \mathrm{dm}^{-3}\right)$ との関係は，次式のように表された。

$$
y=10^{0.048 t+1.80}(0 \leqq t \leqq 30)
$$

APA に吸着したウラン $(\mathrm{V})$ は, $0.03 \mathrm{~mol} \cdot \mathrm{dm}^{-3}$ 濃度以上の過酸化水素と $0.5 \mathrm{~mol} \cdot \mathrm{dm}^{-3}$ 濃度以上 の水酸化ナトリウムを含有する水溶液により効率よく溶離できた。APA 吸着ウラン(VI)は亜硫酸ナト リウム，ヒドラジンなど還元剂を含むアルカリ性化合物の水溶液でも溶離できたことから，ウラン( VI) のウラン $(\mathrm{N})$ への還元反応溶離が考えられた。

\section{1 緒 言}

石油ショックや地球温暖化現象など問題が起こるごとに，石油 に代わるエネルギー資源としてウランの重要性が見直されてき た。なかでもウラン資源として，海水中に溶存するウラン回収の 検討は，小資源国の日本で盛んに行われている。ウラン回収に用 いられる分離剤は, チタン系複合材 ${ }^{3 / 4)}$, アミドオキシム型キレー 卜樹脂5) 7)，ホスホン酸型イオン交換樹脂8)，大環状へキサカルボ ン酸泉などの研究が多く見られる。著者らは，さきにポリ(塩化ビ ニル）とジェチレントリアミンとの反応により合成したアミ， 化樹脂に,さらにエピクロロヒドリンとアニリンを反応させた樹

住友化学工業株式会社大阪研究所, 554 大阪市此花区春 日出中 3-1-98

** 住友化学工業株式会社愛媛工場, 792 新居浜市惣開

1）この報文を “分離機能性樹脂に関する研究(第 5 報)”とす る.

2）前報(第 5 報)，松田公昭，日化，1991， 161 .

3）尾方 界, 海水誌, 24, 197(1971).

4）加藤俊作, 菅坡和彦, 藤井綾子, 高木憲夫, 宮井良孝, 海 水誌, 31, 7(1977).

5）江川博明, 原田日路史, 野中敬正, 日化, 1980, 1767.

6) L. Astheimer, H. J. Schenk, E. G. Wite, K. Schwochau, Sep. Sci. Technol., 18, 307(1983).

7) C. A. Fetcher, S. Hills, U.S. P., 3, 088, 799(1963).

8) H. Egawa, T.Nonaka, M.Ikari, J. Appl. Polym. Sci., 29, 2045(1984).

9）田伏岩夫，小夫家芳明，海水誌，36，205(1982).
脂が，海水中のウラニルイオンに対して優れた吸着性を示すこと を報告し ${ }^{10)}$ ，さらにポリアミン置換メチルホスホン酸残基を有す るキレート樹脂が，ウラン $(\mathrm{V})$ 吸着性に優れることも簢単に報告 した ${ }^{11) 12)}$ 。その後さらに検討を重ね, ウラン鉱石の硫酸水溶液浸 出液やリン酸水溶液のウラン $(\mathrm{V})$ 吸着用にポリアミン置換メチル ホスホン酸残基を有するキレート樹脂が有効であり，吸着したウ ラン $(\mathrm{V})$ の溶離に $0.03 \mathrm{~mol} \cdot \mathrm{dm}^{-3}$ 以上の濃度の過酸化水素を溶 存した $0.5 \mathrm{~mol} \cdot \mathrm{dm}^{-3}$ 以上の濃度の水酸化ナトリウム水溶液で容 易に溶離できることを見いだした。本報では，これらの検討結果 について報告する。

\section{2 実験}

\section{1 ウラン吸着用樹脂}

2.1 .1 ポリアミン置換メチルホスホン酸型キレート樹脂：既 報に準じ10)多孔質ポリ(塩化ビニル)にトリエチレンテトラミンを 反応させて得た，酸交換容量が $8.3 \mathrm{mmol} \cdot \mathrm{g}^{-1}$ のアミノ化樹脂 $130 \mathrm{~g}$ に，木スホン酸 $210 \mathrm{~g} ， 36 \%$ 塩酸水溶液 $430 \mathrm{~g}, 35 \%$ 小 ルマリン $210 \mathrm{~g}$ を加え, 95 $100^{\circ} \mathrm{C}$ で 4 時間反応を行い, 分子中 に $2.29 \mathrm{mmol} \cdot \mathrm{g}^{-1}$ ポリアミン置換のメチルホスホン酸残基を有

10）松田公昭，鴨田 勝，日化，1990，1387.

11）松田公昭, 日化, 1991，161.

12）片岡有信, 松田公昭, 越智賢二, 芦田啓次, 特公 平 227288 (1990).

13) Y. Kataoka, M. Matsuda, M. Kamoda, E. P., 0065120 B 1 (1985). 
するキレート樹脂（以下 APA と略記する）を得た ${ }^{13)}$ 。

2.1 .2 ホスホン酸型イオン交換樹脂：既報 ${ }^{14)}$ に準じスチレ ンージビニルベンゼン共重合樹脂をクロロメチル化し，三塩化リ ンを反応させた後，加水分解および酸化処理して分子中に 3.6 $\mathrm{mmol} \cdot \mathrm{g}^{-1}$ のホスホン酸残基を有するイオン交換樹脂（以下, PAR と略記する) を得た。

2.1.3 第四級アンモニウム塩残基を有するイオン交換樹脂 : 市肘の第四級アンモニウム塩型のイオン交換樹脂 $1 \mathrm{dm}^{3}$ に 2 $\mathrm{mol} \cdot \mathrm{dm}^{-3}$ 濃度の塩酸水溶液 $5 \mathrm{dm}^{3}$ を加党 1 時間かきまぜを行っ た後, 沪過水洗乾燥して得た分子中に $3.13 \mathrm{mmol} \cdot \mathrm{g}^{-1}$ の第四級 アンモニウム塩残基を有するイオン交換樹脂を用いた。

2.1 .4 抽出試薬：市販の bis-(2-ethylhexyl)phosphinic acid (B 2 EHPA), tributyl phosphate (TBP), trioctylamine (TOA), triphenylphosphine oxide (TPO), trioctylphosphine oxide (TOPO) の抽出試薬は, イオン交換水で洗浄を行い水溶性化合物 をあらかじめ除去し，無水硫酸ナトリウムで脱水処理を行った後， $0.05 〜 1.0 \mathrm{~g}$ をへキサン $30 \mathrm{~cm}^{3}$ に溶解した混合溶液を抽出剂と して使用した。

\section{2 ウラン (VI) 試験液}

既報 ${ }^{10)}$ に準じ調製した炭酸ウラニルナトリウムまたは市販特級 試薬の硝酸ウラニルの所定量と硫酸, リン酸または塩化ナトリウ ムの所定量を,イオン交換水または海水に溶解したものを用いた。

\section{3 吸着実験}

2.3.1 pH の異なる水溶液のウラン (VI) 吸着試験：硫酸また は水酸化ナトリウムを加党 $\mathrm{pH}$ を調整した $100 \mathrm{mg} \cdot \mathrm{dm}^{-3} \mathrm{U}(\mathrm{V})-$ $30 \mathrm{~g} \cdot \mathrm{dm}^{-3} \mathrm{NaCl}$ の $25^{\circ} \mathrm{C}$ の水溶液 $30 \mathrm{~cm}^{3}$ に $0.5 \mathrm{~g}$ の APA を 加光， 3 時間ふりまぜ後水相中のウラン $(\mathrm{V})$ 濃度をアルセナゾIII 法による比色分析を既報 ${ }^{15)}$ に準じ行った。

\subsection{2 塩化ナトリウム濃度の異なる水溶液のウラン(VI) 吸着}

試験：塩化ナトリウム濃度の異なる $100 \mathrm{mg} \cdot \mathrm{dm}^{-3}-\mathrm{U}(\mathrm{V})-\mathrm{pH} 4.5$ の水溶液 $30 \mathrm{~cm}^{3}$ に $0.5 \mathrm{~g}$ の APA を加光 2.3.1 項に準じた方 法で処理した。

2.3 .3 ウラン $(\mathrm{VI})$ 吸着速度試験 : $100 \mathrm{mg} \cdot \mathrm{dm}^{-3}-\mathrm{U}(\mathrm{V})$ 濃度 のウラン富化海水または $80 \mathrm{mg} \cdot \mathrm{dm}^{-3}-\mathrm{U}(\mathrm{V})-100 \mathrm{~g} \cdot \mathrm{dm}^{-3}-\mathrm{H}_{2} \mathrm{SO}_{4}$ の水溶液 $0.5 \mathrm{dm}^{3}$ に $5.0 \mathrm{~g}$ の $\mathrm{MC}-95$ を加え, かきまぜを行っ た。所定時間後に液の試料採取を行い, 水相中のウラン $(\mathrm{U})$ 濃度 を分析した。

2.3 .4 平衡吸着試験：ウラン( $\mathrm{U}$ ) 試験液 $30 \mathrm{~cm}^{3}$ に樹脂 0.05 $\sim 1.0 \mathrm{~g}$ または抽出試薬 $0.05 \sim 1.0 \mathrm{~g}$ をへキサン $30 \mathrm{~cm}^{3}$ に溶解 した混合溶液を加え，3時間ふりまぜを行った。樹脂または抽出 剂へのウラン $(\mathrm{V})$ 吸着量は，ふりまぜ前後の水相中のウラン $(\mathrm{V})$ 濃度差分が，樹脂または抽出剂と反応したものとして求めた。

2.3.5 吸着ウラン (VI)のバッチ溶離試験 : $21.5 \mathrm{~g}-\mathrm{U} \cdot\left(\mathrm{dm}^{3}\right.$ $\mathrm{APA})^{-1}$ または $13.1 \mathrm{~g}-\mathrm{U} \cdot\left(\mathrm{dm}^{3} \mathrm{~A}-101 \mathrm{D}\right)^{-1}$ のウラン(V)を吸 着した APA および A-101 D の各 $1 \mathrm{~cm}^{3}$ に各種組成の溶離液 $50 \mathrm{~cm}^{3}$ を所定温度で 3 時間ふりまぜを行った後, 水相中のウラ ン濃度分析を行い，樹脂から溶離したウラン $(\mathrm{V})$ 量または溶離率 を求めた。

2.3.6 カラム吸着, 溶離試験 : $213 \mathrm{mg} \cdot \mathrm{dm}^{-3} \mathrm{U}(\mathrm{V})-300 \mathrm{~g} \cdot$ $\mathrm{dm}^{-3} \mathrm{H}_{3} \mathrm{PO}_{4}$ 組成の水溶液を, $5 \mathrm{~cm}^{3}$ の APA を充填した内径

14）江川博明，高分子加工，32，86(1983).

15）大西 寛, 桶田行雄, 分析化学, 14, 1141(1965).
$12 \mathrm{~mm}$ カラムに SV $20 \mathrm{~h}^{-1}$ の速度で通液を行った。次いで水洗 後 $1.0 \mathrm{~g} \cdot \mathrm{dm}^{-3} \mathrm{H}_{2} \mathrm{O}_{2}-0.5 \mathrm{~mol} \cdot \mathrm{dm}^{-3} \mathrm{NaOH}$ 水溶液を $\mathrm{SV} 10 \mathrm{~h}^{-1}$ の速度で流し, APA に吸着したウラン(U) の溶離を行った。皮 洗後, 2 回目以降の吸着, 溶離を 1 回目と同方法で行った。

\section{3 結果および考察}

\section{1 吸着におよばす $\mathbf{p H}$ の影響}

$\mathrm{APA}$ の各 $\mathrm{pH}$ の異なる水溶液中のウラン( $\mathrm{U}$ ) 吸着性を調へ た。吸着試験前後のウラン濃度差分が MC-95 に吸着されたもの として求めたウラン $(\mathrm{V})$ 吸着量と $\mathrm{pH}$ との関係を図 1 に示した。 APA は, pH の低い酸性雾囲気下のウラン( た。したがって・APA は, ウラン鉱石の硫酸浸出液およびリン酸 製造工程液などの鉱酸水溶液中のウラン $(\mathrm{U})$ 吸着除去用として相 応しく用いることができると考えられる。

\section{2 吸着におよぽす共存塩の影響}

塩化ナトリウム濃度が $0 \sim 200 \mathrm{~g} \cdot \mathrm{dm}^{-3}-\mathrm{pH} 4.5$ の水溶液のウラ ン( $\mathrm{V})$ 吸着性を調べた。ウラン $(\mathrm{V})$ 吸着量と塩化ナトリウム濃度 との関係を図 2 に示した。APA は，塩化ナトリウムのような無 機塩を高濃度に溶存する水溶液中のウラン $(\mathrm{V})$ に対しても良好な 吸着性を示すことがわかった。

\section{3 吸着速度}

ウラン $(\mathrm{V})$ 富化海水扣よび $100 \mathrm{~g} \cdot \mathrm{dm}^{-3}$ 濃度の硫酸水溶液中 のウラン $(\mathrm{V})$ に対する APA の吸着速度を調べた。吸着処理時間

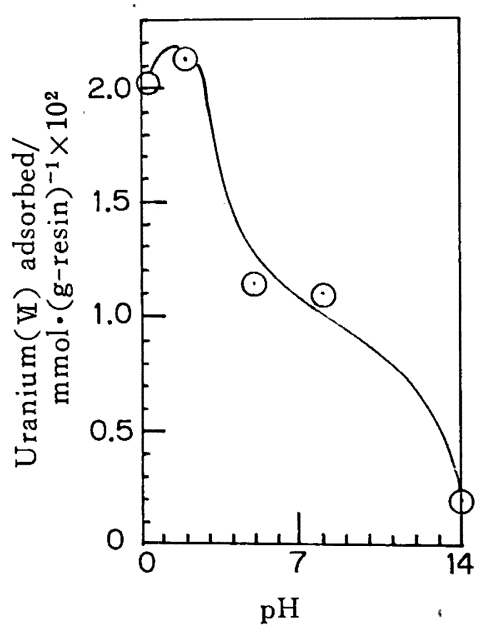

Fig. 1 Effect of $\mathrm{pH}$ on the adsorption of uranium(V) on APA

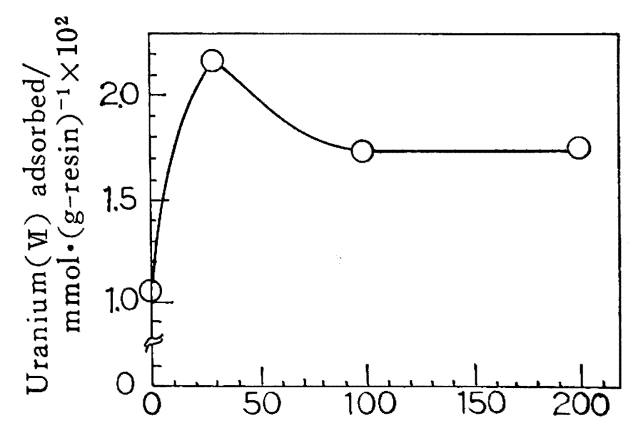

Sodium chloride concentration $/ \mathrm{g} \cdot \mathrm{dm}^{-3}$

Fig. 2 Effect of sodium chloride concentration on the adsorption of uranium( $U$ ) on APA 


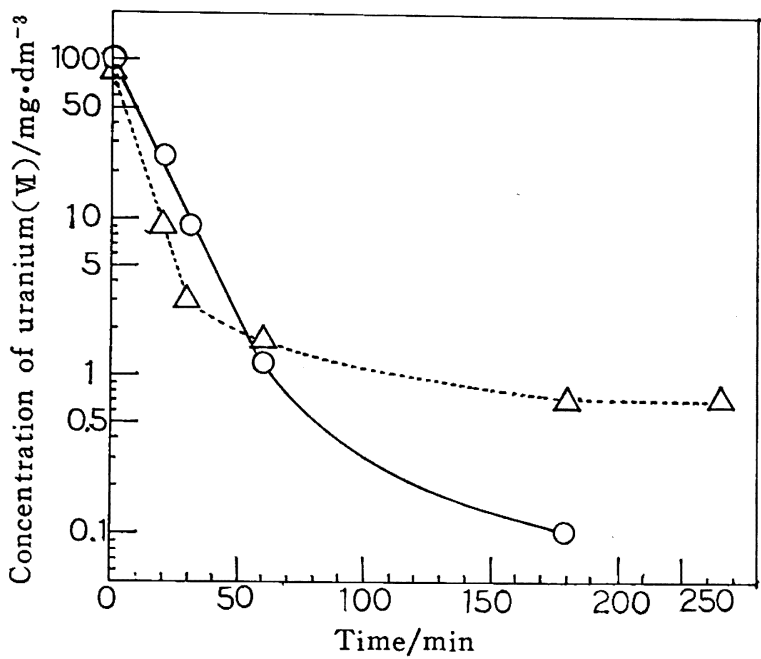

Fig. 3 Adsorption rate of uranium(V) in enriched sea water or sulfuric acid aq. soln. on APA

- - - Uranium( ( $---\triangle---: 100 \mathrm{~g} \cdot \mathrm{dm}^{-3}-\mathrm{H}_{2} \mathrm{SO}_{4}$ aq. soln

に対するウラン $(\mathrm{V})$ 濃度および吸着率の関係を図 3 に示した。何 れの液の昜合も樹脂添加直後のウラン $(\mathrm{V})$ の吸着速度は速く, 1 時間後には $99 \%$ 以上のウランを吸着した。吸着処理初期時の ウラン $(\mathrm{H})$ 濃度 $\left(y: \mathrm{mg} \cdot \mathrm{dm}^{-3}\right)$ と処理時間 $(t: \min )$ との間に 次式のような関係が成り立った。

$$
\begin{array}{ll}
\text { 海水: }: y=10^{-0.092 t+2.00} & (0 \leqq t \leqq 60) \\
\text { 硫酸 : } y=10^{-0.048 t+1.90} & (0 \leqq t \leqq 30)
\end{array}
$$

\section{4 吸着等温線}

3.4.1 APA と PAR の吸着性比較: ウラン( $\mathrm{V})$ 富化海水, $100 \mathrm{~g} \cdot \mathrm{dm}^{-3}$ 硫酸, $30 \mathrm{~g} \cdot \mathrm{dm}^{-3}$ リン酸の各水溶液中のウラン $(\mathrm{V})$ に対する APA と PAR の平衡吸着試験を行い, 図 4 に示す吸着 等温線を得た。ホスホン酸型イオン交換樹脂の PAR は, 江川 ${ }^{14)}$ の結果と同様に海水中のウラン( $\mathrm{H}$ ) に対して優れた吸着性 (100 $\mathrm{mg} \cdot \mathrm{dm}^{-3} \mathrm{U}(\mathrm{V})$ に拈ける吸着容量： $\left.0.2 \mathrm{mmol} \cdot \mathrm{g}^{-1}\right)$ を示した。 しかし, $100 \mathrm{~g} \cdot \mathrm{dm}^{-3}$ 硫酸中のウラン(U) に対する PAR の吸着 性 $\left(100 \mathrm{mg} \cdot \mathrm{dm}^{-3} \mathrm{U}(\mathrm{V})\right.$ での吸着量 : $\left.0.02 \mathrm{mmol} \cdot \mathrm{g}^{-1}\right)$ は, 海水 系に比較し小さく, $300 \mathrm{~g} \cdot \mathrm{dm}^{-3}$ リン酸中のウラン $(\mathrm{V})$ に対して まったく吸着性を示さなかった。一方，ポリアミン置換メチルホ スホン酸型キレート樹脂の APA は，何れの系のウラン(V) に 対しても高吸着容量 $\left(100 \mathrm{mg} \cdot \mathrm{dm}^{-3} \mathrm{U}(\mathrm{V})\right.$ での吸着量 (mmol・ $\left.\mathrm{g}^{-1}\right)$ : 硫酸 0.2 , リン酸 0.05 , 富化海水 0.05$)$ でかつ低濃度ま で除去できた。以上の結果から海水中のウラン( $\mathrm{V})$ 回収には, APA の 3〜4 倍吸着量の大きい PAR が, 鉱酸中のウラン $(\mathrm{V})$ 回収には, PAR の数〜数十倍の吸着量を有する APA が適して いることがわかった。

3.4.2 APA と強塩基性イオン交換樹脂の吸着性比較 : ウラン 鉱石の硫酸浸出液中のウランは, 強塩基性のイオン交換樹脂で吸 着を行い, 浸出液よりも高濃度の硫酸により溶離を行ら方法が工 業的に採用されている。強塩基性イオン交換樹脂の A-101 D と の比較を行い, APA の本分野への応用の可能性を調べた。図 5 に, それぞれの樹脂の 30 または $100 \mathrm{~g} \cdot \mathrm{dm}^{-3}$ 濃度の硫酸水溶液 中のウラン $(\mathrm{V})$ に対する平衡吸着等温線を示した。酸濃度の違い

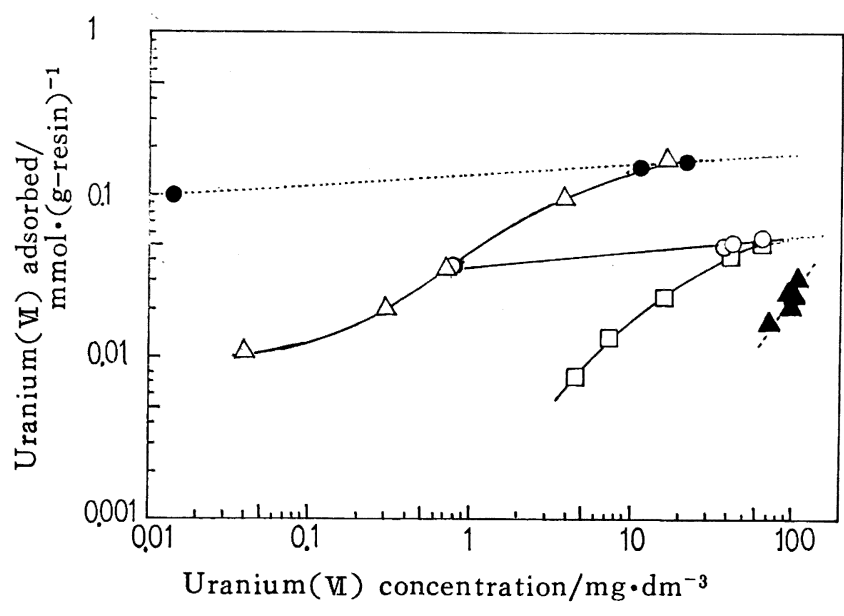

Fig. 4 Adsorption isotherms of uranium( $V$ ) in various aq. soln. on each resin of APA or PAR

Aq. soln. ; -O--O-- : Uranium enriched sea water $-\Delta^{--\Delta---: ~} 100 \mathrm{~g} \cdot \mathrm{dm}^{-3} \mathrm{H}_{2} \mathrm{SO}_{4}$ aq. soln $-\square-: 300 \mathrm{~g} \cdot \mathrm{dm}^{-3} \mathrm{H}_{3} \mathrm{PO}_{4}$ aq. soln

Resin; White key APA, Black key PAR

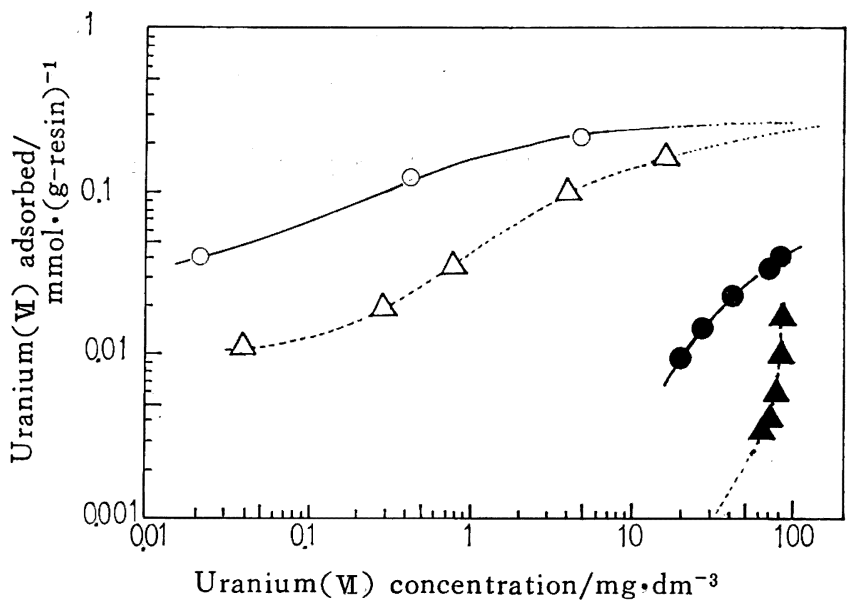

Fig. 5 Adsorption isotherms of uranium(V) in an aq. sulfuric acid soln. of a different concentration on each resin of APA or A-101 D

Aq. soln. ; $\mathrm{O}, \mathrm{O}: 30 \mathrm{~g} \cdot \mathrm{dm}^{-3} \mathrm{H}_{2} \mathrm{SO}_{4}$ aq. sosn., $\triangle, \mathbf{\Delta}$ : $100 \mathrm{~g} \cdot \mathrm{dm}^{-3} \mathrm{H}_{2} \mathrm{SO}_{4}$ aq. soln., Resin; White key APA, Black key A-101 D

による四着量の差は, APA の方が A-101 D よりも大きい。例 えば両樹脂のウラン平衡濃度 $20 \mathrm{mg} \cdot \mathrm{dm}^{-3}$ における酸濃度差間 の吸着量差の比は，（3）式の絬果に示すようにAPA の方が A-101 D の 13.8 倍大きい。さらに同一濃度に拈けるウラン （V）の吸着容量は，APA の方が A-101 D の 30〜300 倍大き い。

$$
\frac{\mathrm{APA} \text { のU吸着量の差 }}{\mathrm{A}-101 \mathrm{D} \text { のU吸着量の差 }}=\frac{(0.30-0.17)}{(0.01-0.0006)}=13.8
$$

以上の結果から，APA を現行のウラン回収プロセスに応用展 開することは, 可能と考えられた。

3.4 .3 抽出剂による鉱酸水溶液中のウラン(VI) 抽出 : 2.3 .4 項の方法で各種抽出剤の $100 \mathrm{~g} \cdot \mathrm{dm}^{-3}$ 䟴度硫酸拉よび $300 \mathrm{~g} \cdot \mathrm{dm}^{-3}$ 
濃度リン酸の各水溶液中のウラン $(\mathrm{U})$ の抽出性を調べた。平衡吸 着等温線の結果を図 6,8 に, 図 6 の実験に拈いて抽出剤中のウ ラン $(\mathrm{V})$ 濃度に対する硫酸水溶液中残存ウラン $(\mathrm{V})$ 濃度の比（分 配比) と $30 \mathrm{~cm}^{3}$ の硫酸水溶液に添加した抽出剤量との関係を図 7 に示した。APA は, 単一の抽出剤の 10 倍以上のウラン( $\mathrm{U}$ ) 吸着量を有し， 2 種類の抽出剂の組み合わせ系の何れよりもなお 吸着性に優れる結果を得た。

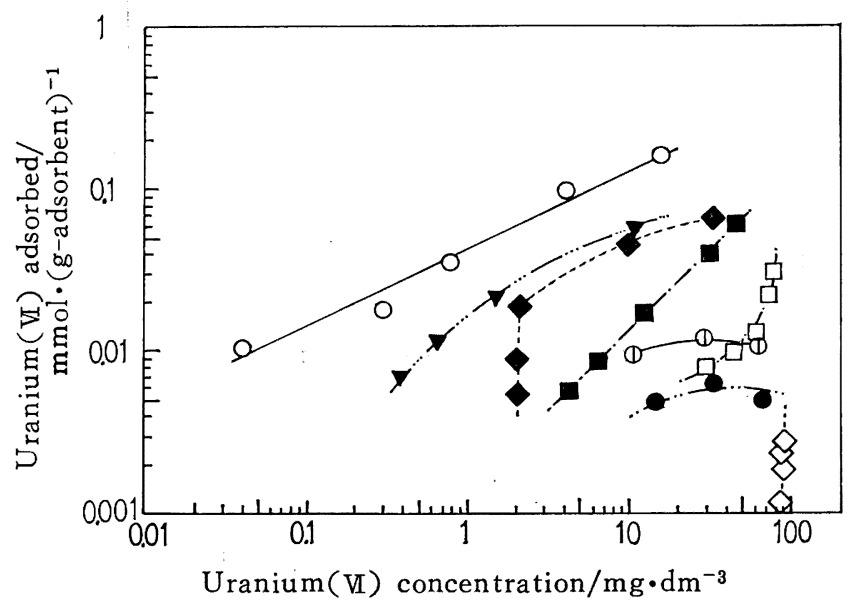

Fig. 6 Adsorption isotherms of uranium(V) in $100 \mathrm{~g}$. $\mathrm{dm}^{-3}-\mathrm{H}_{2} \mathrm{SO}_{4}$ aq. soln. on various adsorbents

Adsorbent ; -- $\diamond---$ : TBP, -- -- : TBP+B 2

EHPA, $\cdot \square-$ : : TOA, $-\square-\cdot$ : TOA + B 2

EHPA, ․-. - B 2 EHPA, -O- : APA

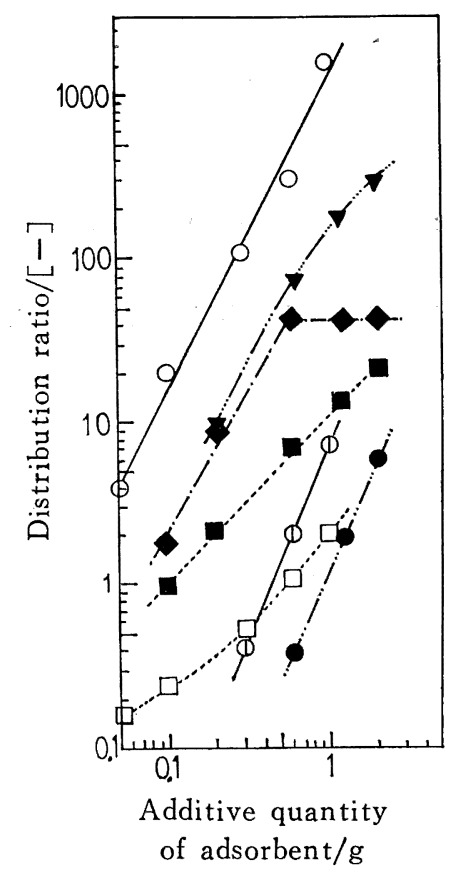

Fig. 7 Relationship between additive quantities of various adsorbents and distribution ratio

Adsorbent ; - - : : TBP+B 2 EHPA, -- $\square---$ : TOA, --- $---:$ TOA+B 2 EHPA, . - - - : : TPO+B 2 EHPA, -(1)-: B 2 EHPA, -O- : APA

Distribution ratio of TBP was below 0.1

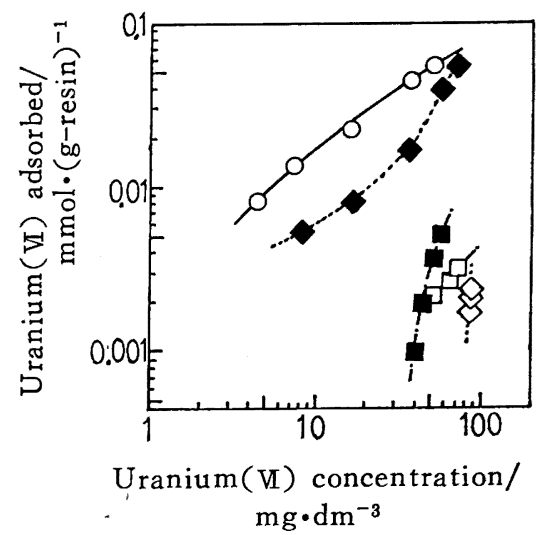

Fig. 8 Adsorption isotherms of uranium( $(\mathrm{l})$ in $300 \mathrm{~g}$. $\mathrm{dm}^{-3} \mathrm{H}_{3} \mathrm{PO}_{4}$ aq. soln. on various adsorbents

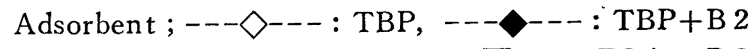
EHPA, - $\square-\cdot:$ TOA, .- $-\cdot$ : $\mathrm{TOA}+\mathrm{B} 2$
EHPA, -O- : APA

\subsection{APA に吸着したウラン(VI) の溶離}

3.5 .1 溶離剤スクリーニング : 2.3.5 項の方法で APA およ び A-101 D に吸着したウラン( $\mathrm{I})$ の溶離の検討を行った。溶離 結果を表 1 に示した。A-101 D の場合, 表 1 に示した何れの溶離 剤も使用が可能であるが, APA の場合, 過酸化水素を溶存した 水酸化ナトリウムの水溶液が最も効果的であることがわかった。

さらに過酸化水素-水酸化ナトリウム水溶液系の溶離剂組成の 最適化を計るために, 過酸化水素および水酸化ナトリウムの濃 度を変えて試験を行った。その結果を図 9 に示した。この結果 から, $0.03 \mathrm{~mol} \cdot \mathrm{dm}^{-3}$ 以上の濃度の過酸化水素でかつ $0.5 \mathrm{~mol}$. $\mathrm{dm}^{-3}$ 以上の濃度の水酸化ナトリウムからなる溶離剤が, APA に 吸着したウラン( $\mathrm{Y}$ )の溶離に最も適していることがわかった。

3.5.2 吸着, 溶離機構: 固体の APA が優れた吸着性を示す 理由は, ポリアミン置換メチルホスホン酸残基が, 偽平面六配位 をとるウラニルイオンと（4）式の反応により，図 10 の模式図 に示すような安定な配位状態をとるためと考えられる。

吸着: $\mathrm{UO}_{2}{ }^{2+}+\mathrm{RH}_{2} \longrightarrow \mathrm{UO}_{2} \cdot \mathrm{R}+2 \mathrm{H}^{+}$

APA に吸着したウラン $(\mathrm{V})$ の過酸化水素を溶存した水酸化ナト リウム水溶液による溶離は, 酸化に起因した反応と考兄次亜塩素 酸ナトリウム水溶液による溶離も試みたが予期した効果を得るに いたらなかった。過酸化水素の水溶液は, 酸性または中性でへキ サシアノ鉄 (II)酸カリウムをへキサシアノ鉄(III)鉄カリウムに酸 化するが、アルカリ性でへキサシアノ鉄(III)酸カリウムをへキサ

Table 1 Elution of uranium(V) adsorbed on each resin of APA and A-101 D

Eluent

Elution rate $(\%)$

$30 \mathrm{~g} \cdot \mathrm{dm}^{-3} \mathrm{H}_{2} \mathrm{SO}_{4}$

$100 \mathrm{~g} \cdot \mathrm{dm}^{-3} \mathrm{H}_{2} \mathrm{SO}_{4}$ A-101 D APA

$30 \mathrm{~g} \cdot \mathrm{dm}^{-3} \quad \mathrm{H}_{2} \mathrm{SO}_{4}-1 \mathrm{~g} \cdot \mathrm{dm}^{-3} \mathrm{H}_{2} \mathrm{O}_{2}$ $100 \mathrm{~g} \cdot \mathrm{dm}^{-3} \mathrm{H}_{2} \mathrm{SO}_{4}-1 \mathrm{~g} \cdot \mathrm{dm}^{-3} \mathrm{H}_{2} \mathrm{O}_{2}$ $40 \mathrm{~g} \cdot \mathrm{dm}^{-3} \mathrm{NaOH}-1 \mathrm{~g} \cdot \mathrm{dm}^{-3} \mathrm{H}_{2} \mathrm{O}_{2}$

$80 \mathrm{~g} \cdot \mathrm{dm}^{-3} \mathrm{NaOH}-78 \mathrm{~g} \cdot \mathrm{dm}^{-3} \mathrm{Na}_{2} \mathrm{~S}$

45. 4

0.2

63.8

47.5

63.1 0.2

65. 1 1. 0

64.3 


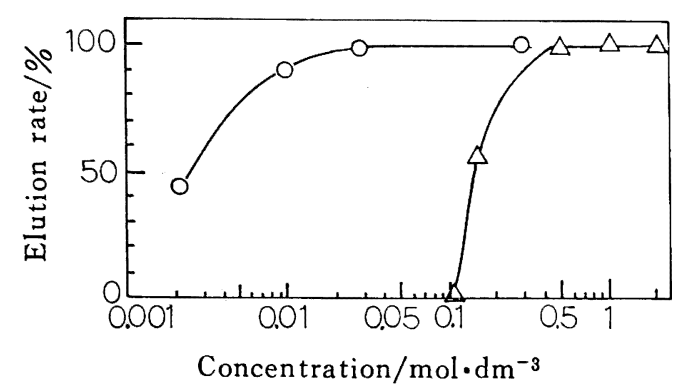

Fig. 9 Effect of concentration of hydrogen peroxide or sodium hydroxide on the elution of uranium(V) adsorbed on APA

Eluent ; $\bigcirc: 0.002 \sim 0.30 \mathrm{~mol} \cdot \mathrm{dm}^{-3} \mathrm{H}_{2} \mathrm{O}_{2}-0.5 \mathrm{~mol} \cdot \mathrm{dm}^{-3}$ $\mathrm{NaOH}$

$\triangle: 0.30 \mathrm{~mol} \cdot \mathrm{dm}^{-3} \mathrm{H}_{2} \mathrm{O}_{2}-0.1 \sim 2.0 \mathrm{~mol} \cdot \mathrm{dm}^{-3}$ $\mathrm{NaOH}$

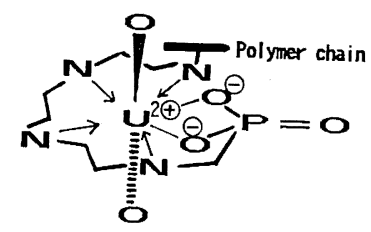

Fig. 10 Speculative model of APA-uranil ion complex

シアノ鉄(II)酸カリウムに還元する ${ }^{16)}$ 。この例に見られるような (5)，（6）式で示す還元反応が, 本実験の APA に吸着したウラ

$$
\begin{aligned}
& \text { 溶離 : } \mathrm{H}_{2} \mathrm{O}_{2} \longrightarrow \mathrm{O}_{2}+2 \mathrm{H}^{+}+2 \mathrm{e}^{-} \\
& \mathrm{UO}_{2} \cdot \mathrm{R}+2 \mathrm{e}^{-} \longrightarrow\left[\mathrm{UO}_{2} \cdot \mathrm{R}\right]^{2-} \\
& \longrightarrow \mathrm{UO}_{2}+\mathrm{R}^{2-}
\end{aligned}
$$

ン( U)の溶離の場合にも関与しているかどらかを確認するため に, 過酸化水素に変え $2 \mathrm{~g} \cdot \mathrm{dm}^{-3} \mathrm{NH}_{2} \mathrm{NH}_{2}-0.5 \mathrm{~mol} \cdot \mathrm{dm}^{-3} \mathrm{NaOH}$ および $2.0 \mathrm{~g} \cdot \mathrm{dm}^{-3} \quad \mathrm{Na}_{2} \mathrm{SO}_{3}-0.5 \mathrm{~mol} \cdot \mathrm{dm}^{-3}-\mathrm{NaOH}$ の組成からな る還元剤を溶存したアルカリ性化合物の水溶液による溶離を表 1 と同方法で試みた。その結果は，予期したと5りそれぞれ 74, $76 \%$ の高溶離率を示した。しかしながら水酸化ナトリウムを含 まない, $50 \mathrm{~g} \cdot \mathrm{dm}^{-3}$ 濃度の亜硫酸ナトリウムの水溶液では, まっ たく溶離しなかった。以上の結果から，APA に吸着したウラン (V)の溶離には, 還元反応が関与しているものと考えられる。し かしながら APA に吸着したウラン( $\mathrm{U}$ )の溶離における還元剂中 の水酸化ナトリウムなどのアルカリ成分の作用機構を解明するに いたらなかった。これら溶離機構および APA 樹脂へのウラン

(V)吸着性などの検討は, 今後の課題としたい。

\section{6 カラム吸着, 溶離試験}

2.3.6 項の方法でリン酸中のウラン( $\mathrm{U}$ ) 吸着, 溶離試験を行っ た。その結果を図 11，12 に示した。1 回目および 10 回目の吸 着量は，それぞれ $55,58 \mathrm{mg}-\mathrm{U} \cdot\left(5 \mathrm{~cm}^{3}-\mathrm{APA}\right)^{-1}$ であり, 10 回 のくり返しの試験では，劣化は認められなかった。

16）柴田婎次，“無機化学全書 II-1-1”，丸善（1950） p. 247.

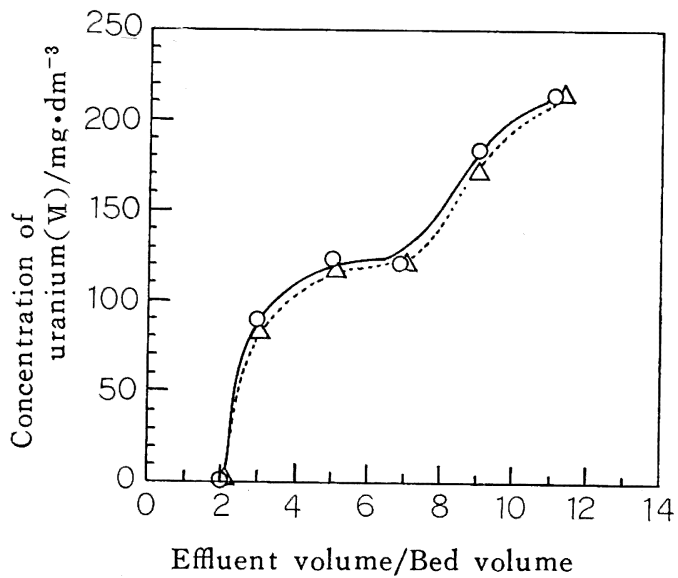

Fig. 11 Break-through curves of uranil ion in $300 \mathrm{~g}$. $\mathrm{dm}^{-3} \mathrm{H}_{3} \mathrm{PO}_{4}$ aq. soln.

$-\bigcirc-: 1$ st cycle, $---\triangle---: 10$ th cycle

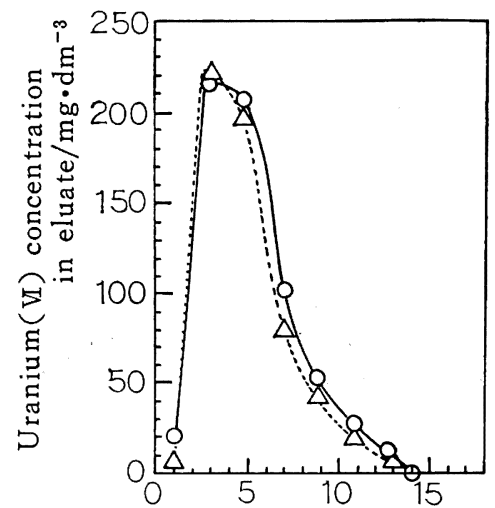

Elution volume/Bed volume

Fig. 12 Elution curves of uranium(V) adsorbed on APA

$-\bigcirc-: 1$ st cycle, $---\triangle---: 10$ th cycle

\subsection{APA によるリン酸中のウラン(VI) 回収フロー}

米国, 欧州など大規模なりン酸製造工場の工程液中のウラン （V）を APA を用いて回収することを想定した製造フローを図 13 に提案した。

\section{4 結 論}

ポリアミン置換メチルホスホン酸残基を持ったキレート樹脂 (APA) のウラン (V) 吸着特性を調べ，以下のことを明らかにし た。

（1） APA は $\mathrm{pH} 3$ 以下の酸性水溶液中のウラン（VI）吸着性 に優れており, $100 \mathrm{~g} \cdot \mathrm{dm}^{-3}$ 濃度の硫酸, $300 \mathrm{~g} \cdot \mathrm{dm}^{-3}$ 濃度のリン 酸の各水溶液中のウラン $(\mathrm{V})$ 回収用として使用することができ る。その吸着容量は，ウラン $(\mathrm{V})$ 回収用として工業的に用いられ ている強塩基性イオン樹脂の約 30 倍, 良好なウラン(V) 抽出性 を示す抽出剤 (TOPO+B 2 EAHPA) の 2 ～倍大きい。ホスホ ン酸型のイオン交換樹脂 PAR の硫酸, リン酸中のウラン(V) 吸着性は小さく工業的に使用に耐えられない。

（2）海水中のウラン（VI）に対して APA および PAR の両 樹脂とも良好な吸着性を示した。PAR/APA の吸着容量比は 3 


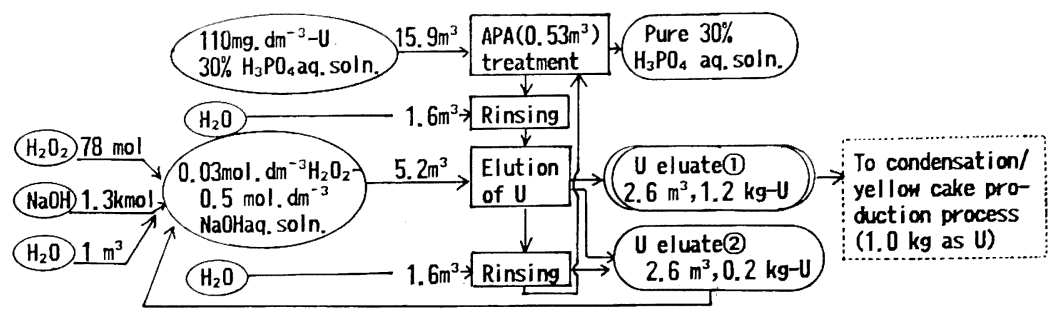

Fig. 13 Block flow sheet for recovery of uranium(V) in an aq. phosphoric acid soln. with polyamine-substituted methylphosphonic acid moiety containing chelate resin

4 であり, 海水ウラン $(\mathrm{V})$ 回収用としては, PAR が適する。

(3) APA のウラン $(\mathrm{V})$ 吸着速度は速く, 吸着初期の吸着量 $\left(y: \mathrm{mg} \cdot \mathrm{dm}^{-3}\right)$ と処理時間 $(t: \mathrm{min})$ との関係は, 次式のように 表された。

海水 : $y=10^{-0.032 t+2.00} \quad(0 \leqq t \leqq 60)$

硫酸 : $y=10^{-0.048 t+1.90} \quad(0 \leqq t \leqq 30)$
（4） APA に吸着したウラン $(\mathrm{V})$ は, $0.03 \mathrm{~mol} \cdot \mathrm{dm}^{-3}$ 濃度以 上の過酸化水素と $0.5 \mathrm{~mol} \cdot \mathrm{dm}^{-3}$ 濃度以上の水酸化ナトリウムの 混合水溶液により溶離ができる。

（5）リン酸製造工程液中のウラン（U）を回收するフローを 提案した。

\title{
Uranium (VI) Adsorption Properties of a Chelating Resin Containing Polyamine-substituted Methylphosphonic Acid Moiety ${ }^{\dagger}$
}

\author{
Masaaki MAtsudA* and Yoshirou Aкıуоsні** \\ Osaka Research Laboratory, Sumitomo Chemical Co., Ltd. ; Kasugade, Naka, \\ Konohana-ku, Osaka-shi 554 Japan \\ ** Ehimework, Sumitomo Chemical Co., Ltd.; Sobiraki-cho, Niihama-shi 792 Japan
}

Uranium(VI) adsorption and desorption properties of a chelating resin containing polyamine-substituted methylphosphonic acid moiety of $2.29 \mathrm{mmol} / \mathrm{g}$-resin (APA) were examined. Uranium(V) adsorption properties of several ion exchange resins and extractant agents which were known as excellent adsorbents for uranium( $V$ ), were examined together for a comparison with those of APA. Uranium(VI) adsorption capacity of APA at the concentration of $100 \mathrm{mg} \cdot \mathrm{dm}^{-3}$-urainum(V) in $100 \mathrm{~g} \cdot \mathrm{dm}^{-3}-\mathrm{H}_{2} \mathrm{SO}_{4}$ aq. soln., $190 \mathrm{~g} \cdot \mathrm{dm}^{-3}-\mathrm{H}_{3} \mathrm{PO}_{4}$ aq. soln. and uranium enriched sea water, was $0.2,0.05$ and $0.05 \mathrm{mmol} \cdot \mathrm{g}^{-1}$ respectively. The adsorption capacity of APA for uranium(VI) in these solutions was larger than that of another adsorbents, except the adsorption of uranium(VI) in enriched sea water on ion exchange, resin containing phosphoric acid moiety (adsorption capacity $; 0.2 \mathrm{mmol} \cdot \mathrm{g}^{-1}$ ). Uranium(V) adsorption rate on APA was high and the relation between treatment time $(t: \min )$ and uranium(V) concentration $\left(y: \mathrm{mg} \cdot \mathrm{dm}^{-3}\right)$ in $100 \mathrm{~g} \cdot \mathrm{dm}^{-3} \mathrm{H}_{2} \mathrm{SO}_{4}$ aq. soln. after treatment, was shown as following equation, $y=20^{0.048 t+1.90}(0 \leqq t \leqq 30)$.

The adsorbed uranium(VI) on APA was able to be eluted with a mixed aq. soln. of hydrogen peroxide and sodium hydroxide and also was able to be eluted with an aq. alkaline soln. dissolved reduction agents such as sodium sulfite and hydrazine. From these results, it was thought that uranium(V) adsorbed on APA was eluted due to the reduction to uranium (IV) by these eluents.

$\dagger$ Studies on Functional Polymer for Separation. V. 